\title{
PENGARUH FLEXTIME TERHADAP JUMLAH PESANAN GOJEK DI KOTA BANDAR LAMPUNG
}

\author{
Sri Suyarti1, Yakub Aprilianto ${ }^{2}$ \\ Program Studi Manajemen, Sekolah Tinggi Ilmu Ekonomi Gentiaras, Bandar Lampung \\ Email: destawinrst.uyee@gmail.com
}

\section{ABSTRACT}

Online transportation is public transportation that is commonly used but can be operated online both for ordering and payment. Flextime is a system of regulating working hours that gives more freedom to employees that choosing work hour according to their needs. The application of flexible working hours greatly facilitates the driver in doing work; with this the consumer is facilitated to use Gojek facilities.

Based on the calculation, the effect of flextime variable $(X)$ on the order quantity $(Y)$ is $40.1 \%$, and $59.9 \%$ is influenced by other factors. The results of the $T$ test $t$ count $>t$ table $(8,347>1,645)$ means that there is a flextime effect on the number of orders in Gojek Bandar Lampung.

Keywords : flextime, order quantity.

\section{PENDAHULUAN}

\subsection{Latar Belakang}

Transportasi online adalah salah satu bentuk dari penyelenggaraan Lalu Lintas dan Angkutan Jalan yang berjalan dengan mengikuti serta memanfaatkan perkembangan ilmu pengetahuan dan teknologi (Doni,2014). Transportasi online adalah bentuk dari pengembangan potensi dan peran transportasi nasional yang sekaligus mendukung pembangunan ekonomi dan pengembangan wilayah (Ellen,2010). Transportasi online adalah wahana yang digunakan sebagai pemindah dari suatu tempat ke tempat lain dengan agensi-agensi tertentu yang bertanggung jawab dalam hal kepemilikan maupun pengoperasian transportasi yang terkait, hal utama dari transportasi ini yaitu transportasi berbasis mesin canggih dilengkapi dengan fitur pelacak posisi (Brenda,2016). Transportasi online adalah angkutan umum yang biasa digunakan namun dapat dioperasikan secara online, baik untuk pemesanan maupun pembayaran (Adinda,2017).

Berkembangnya bisnis trasportasi online, membuat perusahaan transportasi harus selalu mengevaluasi layanan yang diberikan, seperti driver berkendara dengan benar dan hati-hati, driver menggunakan atribut Gojek agar mudah dikenali, sopan santun, berpenampilan bersih, dan rapi, itu semua merupakan sebuah kode etik yang wajib ditaati oleh mitra Gojek. Hal tersebut berpengaruh terhadap kenyamanan konsumen dan berdampak pada pemesanan secara berulang oleh konsumen. Selain itu, transportasi dalam hal ini adalah, perusahaan harus mampu membangun dan menjaga kepercayaan konsumen.

Flextime adalah sistem pengaturan jam kerja yang memberikan lebih banyak kebebasan kepada karyawan memilih jam kerja sesuai dengan kebutuhan mereka. Maka, kehadiran Gojek menjadi salah satu alternatif bagi masyarakat di tengah persaingan dengan sistem transportasi publik. Transportasi berbasis online yang ternyata dapat memberikan dan menjawab berbagai kekhawatiran masyarakat akan layanan transportasi umum, seperti kemacetan lalu lintas dan ketakutan masyarakat dengan keamanan transportasi umum dijawab dengan kehadiran aplikasi transportasi online yang memberikan kemudahan dan kenyamanan bagi penggunanya.

Penerapan jam kerja yang flexible sangat memudahkan pengemudi dalam 
melakukan pekerjaan, dengan hal ini konsumen dimudahkan untuk menggunakan fasilitas Gojek. Gojek melakukan inovasi dengan mengembangkan fitur yang ditawarkan. Selain layanan transportasi saat ini, driver yang bekerja dengan waktu yang sama setiap hari mendapat penumpang yang berbeda. berusaha memenuhi kebutuhan gaya hidup dan logistik di dalam satu aplikasi. Gojek menambahkan layanan selain jasa transportasi ojek yaitu $G o$ Car, Go Food, Go Mart, Go Send, Go Box, Go Pulsa. Gojek telah beroperasi di 50 kota di Indonesia, salah satunya Kota Bandar Lampung, Lampung.
Go Ride adalah layanan di Gojek, dimana anda akan mengantarkan pelanggan dari tempat penjemputan ke tempat tujuan. Go Ride adalah pilihan transportasi yang memberikan kecepatan, kemudahan pemesanan, dan kemudahan menentukan tujuan konsumen. Pelanggan akan memasukan titik lokasi penjemputan dan titik lokasi tujuan mereka ke dalam aplikasi ketika memesan layanan Go Ride dengan jarak tempuh maksimal $25 \mathrm{~km}$ dari tempat penjemputan.

Gambar 1.

Diagram perbandingan jumlah pesanan driver Gojek di Kota Bandar Lampung

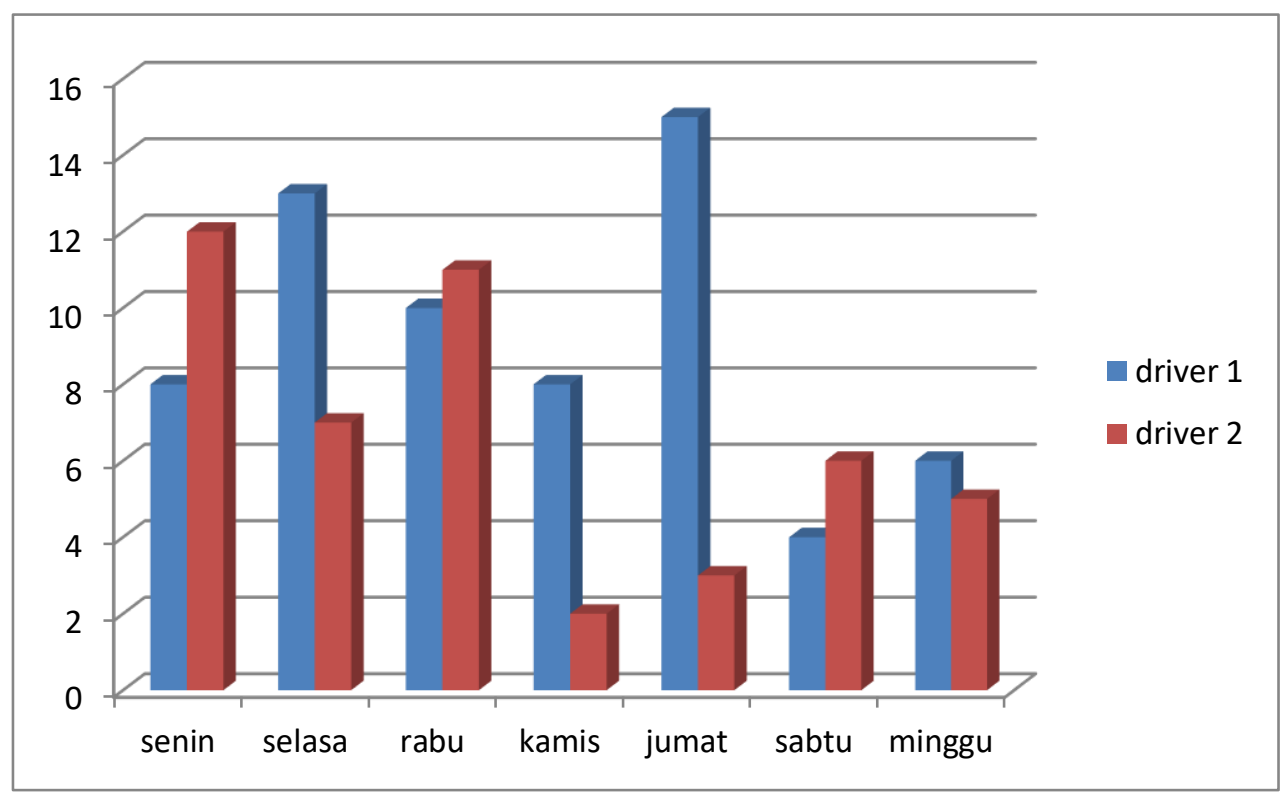

Sumber: Data diolah 2018.

Dari data yang peneliti sajikan baik dalam bentuk tabel maupun grafik terlihat sangat jelas selisih perbedaan driver 1 dengan driver 2 dalam mendapatkan pesanan. Dengan jumlah jam kerja yang sama tetapi mendapatkan pesanan yang berbeda, dalam rata-rata 1 minggu driver 2 mendapat selisih penumpang sebanyak $22,2 \%$. Lalu yang menjadi permasalahan dari kedua driver yang melalui pra research peneliti adalah kedua driver memiliki jumlah jam kerja yang sama tetapi kedua driver mendapatkan jumlah penumpang yang berbeda.

\subsection{Perumusan Masalah}

Apakah terdapat pengaruh flextime terhadap jumlah pesanan Gojek di Kota Bandar Lampung?

\subsection{Tujuan Penelitian}

Untuk menganalisis pengaruh flextime terhadap jumlah pesanan Gojek di Kota Bandar Lampung.

\section{TINJAUAN PUSTAKA}

\subsection{Flextime}

Menurut buku The Economist (2011) flextime sebuah pengaturan yang 
memungkinkan karyawan untuk mengatur jam kerja sendiri dalam batas-batas yang disepakati; biasanya harus mencakup periode tertentu (waktu inti) ketika mereka harus bekerja bakat: bahkan jika buku peraturan perusahaan mengatakan bahwa flexitime diperbolehkan, mereka yang bekerja dari rumah dipandang sebagai uncommitted untuk tim. Menurut Sabeer Dasgupta (2011) penerapan waktu kerja yang fleksibel ini sebenarnya mendatangkan banyak manfaat untuk karyawan dan juga perusahaan. Perusahaan tempatnya bekerja memang sudah menerapakan fleksibilitas waktu.

Menurut Hook dan Higgs (2000, dalam Yustrianthe, 2008)menyebutkan bahwa jam kerja fleksibel (flextime) mengarahkan karyawan untuk bekerja dengan jumlah jam tertentu dengan fleksibilitas yang lebih besar atau bekerja tidak sebanyak jam kerja yang telah ditetapkan di kantor. Dengan demikian, jam kerja fleksibel telah dinilai telah banyak membawa perubahan dalam lingkungan kerja profesional saat ini. Dilain pihak, profesional yang bekerja dilingkungan yang menggunakan jam kerja standar mensyaratkan agar mereka bekerja dalam waktu tertentu dan sebanyak jam yang ditetapkan kantor. Ketetapan jumlah jam kerja standar umumnya mengacu pada aturan ketenaga kerjaan yang.ditetapkan oleh pemerintah sebanyak 8 jam per hari mulai jam 08:00 sampai 17:00 WIB. Akan tetapi, aplikasi yang sesungguhnya sangat tergantung pada kebijakan perusahaan. Fleksibilitas pada jam kerja (flextime) dalam studi ini untuk selanjutnya disebut jam kerja fleksibel.

Triatmoko (2008) menjelaskan bahwa flextime merupakan jadwal kerja yang memberikan kebebasan individu tentang pengaturan waktu kerjanya. Dapat diartikan bahwa flextime menggambarkan suatu pendekatan untuk menggambarkan dampak waktu luang pada jumlah konsumen pengemudi gojek, waktu juga mempunyai posisi bebas penggunaannya waktu tersebut berada diluar kegiatan rutin sehari-hari sehingga dapat dimanfaatkan secara positif guna meningkatkan produktifitas hidup yang efektif dan pengisian waktu luang dapat diisi dengan berbagai macam kegiatan. ketika seseorang akan mengikuti keinginannya sendiri baik untuk beristirahat, menambah pengetahuan atau mengembangkan keterampilannya secara objektif.

Dimensi flextime seperti dimensi waktu terdiri dari tidak digunakan untuk bekerja dan mencari nafkah. Dimensi pengisi waktu terdiri dari kegiatan pilihan sendiri atau waktu yang digunakan untuk kegiatan tertentu. Dimensi fungsi waktu sebagai sarana mengembangkan potensi yang ada. Menurut Astuti (2010) mengenai flextime diukur dengan cara menanyakan kepada orang yang bekerja variabel-variabel yang paling penting dalam pekerjaan mereka.

Dalam penelitian ini flextime diartikan sebagai "Jadwal kerja yang memberikan kebebasan tentang pengaturan waktu kerjanya" Astuti (2010). Menurut Soetarlinah (2008) yang melihat arti istilah waktu luang dari 3 indikator, yaitu:

a. Dimensi waktu, waktu luang sebagai waktu yang tidak digunakan untuk bekerja mencari nafkah, dan mempertahankan hidup.

b. Pengisian waktu luang adalah waktu yang dapat diisi dengan kegiatan pilihan sendiri atau waktu yang digunakan dan dimanfaatkan.

c. Dari sisi fungsi, waktu luang adalah waktu yang dimanfaatkan sebagai sarana mengembangkan potensi, meningkatkan mutu pribadi, kegiatan terapeutik bagi yang mengalami gangguan emosi, sebagai selingan hiburan, sarana rekreasi, sebagai kompensasi pekerjaan yang kurang menyenangkan, atau sebagai kegiatan menghindari sesuatu.

\subsection{Pesanan}

Menurut Kamus Besar Bahasa Indonesia Pesanan adalah suatu aktifitas yang dilakukan oleh konsumen sebelum membeli. Untuk mewujudkan kepuasan konsumen maka perusahaan harus mempunyai sebuah sistem pemesanan yang baik, yang dimaksud pemesanan adalah "proses, perbuatan, cara memesan (tempat,barang,dsb) kepada orang lain". 
Menurut Edwin dan Chris (2009) Pesanan dalam arti umum adalah perjanjian pesanan tempat antara 2 (dua) pihak atau lebih, perjanjian pesanan tempat tersebut dapat berupa perjanjian atas pesanan suatu ruangan, kamar, tempat duduk dan lainnya, pada waktu tertentu dan disertai dengan produk jasanya. Produk jasa yang dimaksud adalah jasa yang ditawarkan pada perjanjian pesanan tempat tersebut, seperti pada perusahaan penerbangan atau perusahaan pelayaran adalah perpindahan manusia atau benda dari satu titik (kota) ketitik (kota) lainnya. Flextime merupakan waktu luang dalam sebuah pekerjaan. Dalam proses berjalannya pekerjaan ada waktu luang yang bertujuan pada jumlah pesanan: 1) Waktu luang dilihat sebagai waktu yang tidak digunakan untuk bekerja mencari nafkah, melaksanakan kewajiban dan mempertahankan hidup. 2) Dalam penggunaan waktu luang menunggu konsumen memesan kepada pengemudi. 3) Pengemudi yang sudah mendapat pesanan dari konsumen dan menjalankan pekerjaannya.

\subsection{Hipotesis}

Ada pengaruh antara flextime terhadap jumlah pesanan Gojek Bandar Lampung.

\section{METODOLOGI PENELITIAN}

\subsection{Jenis Penelitian}

Jenis penelitian yang digunakan untuk penelitian ini adalah penelitian korelasional dan survey untuk mengetahui hubungan antara variabel flextime dan variabel jumlah pesanan pada pengemudi Gojek di Kota Bandar Lampung. Dalam penelitian ini uji yang digunakan meliputi, uji reliabilitas, uji validitas, analisis regresi, uji signifikasi serta uji koefisien determinasi. Tempat penelitian dilaksanakan di Bandar Lampung, pada bulan Mei sampai dengan bulan Juli 2018 dengan responden driver Gojek Bandar Lampung.

\subsection{Populasi Dan Sampel}

Dalam penelitian ini populasi umum mencakup seluruh driver Gojek Bandar Lampung baik yang masih bekerja atau terkena pemutusan hubungan kerja (putus mitra). Sampel dalam penelitian ini adalah pengemudi Gojek Teluk Betung Barat, Teluk Betung Selatan, Panjang, Teluk Betung, Teluk Betung Utara, Tanjung Karang Pusat, Tanjung Karang Barat, Kemiling, Kedaton, Rajabasa, Tanjung Seneng, Sukarame, Sukabumi yang mewakili wilayah Bandar Lampung.

Sugiyono (2013:125) menjelaskan Nonprobability Sampling adalah teknik pengambilan sampel yang tidak memberi peluang/kesempatan sama bagi setiap unsur atau anggota populasi untuk dipilih menjadi sampel. Teknik sampel ini yang digunakan dalam penelitian ini adalah teknik snowball sampling. Snowball Sampling dalah teknik penentuan sampel yang mula-mula jumlahnya kecil lalu kemudian semakin membesar.

\subsection{Teknik Pengumpulan Data}

Dalam penelitian ini teknik yang digunakan adalah wawancara yaitu cara untuk memperoleh data dengan langsung mewawancari langsung ke pusat-pusat informasi atau data mengenai objek yang akan diteliti. Kuisioner dengan menyebarkan daftar pertanyaan-pertanyaan yang harus dijawab atau dikerjakan oleh responden

\subsection{Analisis Kuantitatif}

a. Uji Validitas adalah Uji ketepatan atau ketelitian suatu alat ukur dalam mengukur apa yang sedang ingin diukur. Dalam penelitian ini, peneliti menggunakan uji validitas untuk menguji apakah kuesioner yang peneliti gunakan dapat dikatakan valid. Dalam hal ini pertanyaan yang peneliti gunakan berdasarkan indikator dari variabel-variabel yang diteliti dinyatakan mampu mengungkapkan variabel yang diukur dalam penelitian.

b. Uji realibilitas menurut Sugiono (2005), reliabilitas adalah serangkaian pengukuran atau serangkaian alat ukur yang memiliki konsistensi bila pengukuran yang dilakukan dengan alat ukur itu dilakukan secara berulang. Rumus Uji Reliabilitas Teknik Belah Dua dilakukan dengan cara membagi tes menjadi dua bagian yang relatif sama (banyaknya soal sama), sehingga masing-masing test mempunyai dua macam skor, yaitu skor belahan pertama (awal / soal nomor ganjil) dan 
skor belahan kedua (akhir / soal nomor genap). Koefisien reliabilitas belahan tes dinotasikan dengan $r$ 1/2 1/2 dan dapat dihitung dengan menggunakan rumus yaitu korelasi angka kasar Pearson. Kriteria uji reliabilitas dengan rumus alpha adalah apabila r-hitung lebih besar dari rtabel, maka alat ukur tersebut reliabel dan juga sebaliknya, jika r-hitung lebih kecil dari $r$ tabel maka alat ukur tidak reliabel. Dalam penelitian ini, dilakukan uji reliabilitas dengan menggunakan SPSS for windows dengan model Alpha Cronbach's yang diukur berdasarkan skala Alpha Cronbach's 0 sampai 1 . Jika instrumen itu valid, maka dilihat kriteria penafsiran mengenai indeks $r 11$ sebagai berikut (Arikunto 2010:319) :

c. Uji Normalitas Dan Uji Homogenitas, merupakan salah satu asumsi dari statistik parametrik. Uji normalitas bertujuan untuk menguji normal tidaknya data sampel. Distibusi data yang normal adalah distribusi data yang menyerupai bentuk bel atau genta. Data populasi selalu berdistribusi normal karena setiap populasi mempunyai sifat normal. Data sampel hanya dapat digeneralisasikan pada populasi apabila mempunyai sifat normal sebagaimana populasinya. Bila data sampel berdistribusi normal maka pengolahan datanya dapat menggunakan statistik parametrik dan hasil pengolahan data atas sampel dapat digeneralisasikan kepada populasi. Sedangkan uji homogenitas adalah pengujian mengenai sama tidaknya variansi-variansi dua buah distribusi atau lebih.

\section{d. Uji T}

Uji t dikenal dengan uji parsial, yaitu untuk menguji bagaimana pengaruh masingmasing variabel bebasnya secara sendirisendiri terhadap variabel terikatnya. Uji ini dapat dilakukan dengan mambandingkan $t$ hitung dengan $t \underline{t a b e l}$ atau dengan melihat kolom signifikansi pada masing-masing $t$ hitung.

\section{e. $\quad$ Uji $R^{2}$ (Koefisien Determinasi)}

$\mathrm{R}^{2}$ adalah perbandingan antara variasi $Y$ yang dijelaskan oleh $X$ secara bersamasama dibanding dengan variasi total $Y$. Jika selain $X$ semua variabel di luar model yang diwadahi dalam $E$ dimasukkan ke dalam model, maka nilai $R^{2}$ akan bernilai 1. Ini berarti seluruh variasi $Y$ dapat dijelaskan oleh variabel penjelas yang dimasukkan ke dalam model.

Dalam penelitian ini, uji $\mathrm{R}^{2}$ (koefisien determinasi) peneliti pilih untuk memprediksi seberapa besar kontribusi pengaruh Persepsi harga $(X)$ terhadap jumlah pesanan $(Y)$, dengan syarat hasil uji $F$ dalam analisis regresi bernilai signifikan.

f. Regresi Linier, menurut Kurniawan (2008) regresi linier adalah metode statistika yang digunakan untuk membentuk model hubungan antara variabel terikat (dependen; respon; $Y$ ) dengan satu atau lebih variabel bebas (independen, prediktor, X). Regresi mampu mendeskripsikan fenomena data melalui terbentuknya suatu model hubungan yang sifatnya numerik. Regresi juga dapat digunakan untuk melakukan pengendalian (kontrol) terhadap suatu kasus atau hal-hal yang sedang diamati melalui penggunaan model regresi yang diperoleh. Selain itu, model regresi juga dapat dimanfaatkan untuk melakukan prediksi untuk variabel terikat. Uji regresi peneliti butuhkan untuk menguji seberapa besar pengaruh sebab-akibat antara variabel flextime variabel independen dengan variabel dependen (jumlah pesanan) Model persamaan regresi linier sederhana adalah $\mathrm{Y}=\mathrm{a}+\mathrm{bX}+\mathrm{e}$

\section{HASIL PENELITIAN DAN PEMBAHASAN}

\subsection{Analisis Data dan Hasil Penelitian}

1. Uji validitas dan reliabilitas

Uji Validitas dan reliabilitas diajukan pada 40 responden yang dilakukan dengan teknik snowball. Kriteria pengujian apabila memiliki tingkat korelasi signifikan antara $1 \%$ $5 \%$, maka pengukuran dikatakan valid dan 
sebaliknya apabila memiliki tingkat korelasi signifikan lebih dari $5 \%$ dinyatakan tidak valid. Berdasarkan hasil pengolahan, data pada instrumen penelitian hal ini angket dijelaskan dalam tabel sebagai berikut.

Tabel 1.

Hasil Uji Validitas Kuisioner Flextime

\begin{tabular}{ccc}
\hline Variabel & Validitas & Hasil \\
\hline Butir pernyataan 1 & 0.775 & valid \\
Butir pernyataan 2 & 0.893 & valid \\
Butir pernyataan 3 & 0.787 & Valid \\
Butir pernyataan 4 & 0.905 & Valid \\
Butir pernyataan 5 & 0.868 & Valid \\
Butir pernyataan 6 & 0.830 & Valid \\
\hline
\end{tabular}

Sumber : Sumber: Data diolah 2018.
Tabel 2.

Hasil Uji Validitas Kuisioner Jumlah Pesanan

\begin{tabular}{ccc}
\hline Variabel & Validitas & Hasil \\
\hline Butir pernyataan 1 & 0.775 & Valid \\
Butir pernyataan 2 & 0.893 & Valid \\
Butir pernyataan 3 & 0.787 & Valid \\
Butir pernyataan 4 & 0.905 & Valid \\
Butir pernyataan 5 & 0.868 & Valid \\
Butir pernyataan 6 & 0.830 & Valid \\
\hline Sumber : Data output, 2018. \\
\multicolumn{3}{c}{} \\
Pada pengujian & reliabilitas & instrumen
\end{tabular}
digunakan rumus alpha cronbach dengan membandingkan nilai alpha cronbach dengan nilai 0,6 . Jika nilai alpha cronbach $>0,6$ berarti instrumen tersebut reliabal dan sebaliknya apabila nilai alpha cronbach $<0,6$ berarti instrumen tersebut tidak reliabal.

Tabel 3.

Hasil Uji Realiabilitas

\begin{tabular}{cccc}
\hline Variabel & $\begin{array}{c}\text { Koefisien } \\
\text { Alpha Croncbach }\end{array}$ & Hasil & Kesimpulan \\
\hline Flextime $(\mathrm{X})$ & 0.885 & alpha $>0,6$ & reliabel \\
\hline Jumlah pesanan $(\mathrm{Y})$ & 0.892 & alpha $>0,6$ & reliabel \\
\hline
\end{tabular}

Sumber: Data output, 2018.

Koefisien cronbach's alpha untuk masing-masing item pertanyaan $\geq 0,6$ artinya cronbach's alpha dapat diterima (acceptable) dengan kata lain jawaban responden terhadap pertanyaan yang digunakan untuk mengukur flextime dan Jumlah Pesanan adalah konsisten dan dapat dipercaya (reliable).

\section{Analisis Regresi Linier}

Tabel 4.

Hasil analisis Regresi Coefficientsa

\begin{tabular}{|c|c|c|c|c|c|c|}
\hline \multirow{2}{*}{\multicolumn{2}{|c|}{ Model }} & \multicolumn{2}{|c|}{ Unstandardized Coefficients } & \multirow{2}{*}{$\begin{array}{c}\text { Standardized Coefficients } \\
\text { Beta }\end{array}$} & \multirow{2}{*}{$t$} & \multirow{2}{*}{ Sig. } \\
\hline & & $B$ & Std. Error & & & \\
\hline & (Constant) & 7.015 & 1.488 & & 4.714 & .000 \\
\hline & flextime & .662 & .069 & .634 & 9.624 & .000 \\
\hline
\end{tabular}

a. Dependent Variable: jumlah pesanan

Sumber : Data penelitian diolah dengan PASW versi 18.

Tabel selanjutnya menggambarkan persamaan regresi yaitu $Y=a+b x$

$Y=7,015+0,662 X$

$\mathrm{T}=4,714 \quad 9,624$
Dimana :

$Y=$ Jumlah pesanan.

$\mathrm{X}=$ Flextime. 
Konstanta sebesar 7,015 menyatakan bahwa jika tidak ada Flextime Maka Jumlah pesanan 7,015 .
Koifisien regresi sebesar 0,662 menyatakan bahwa setiap penambahan 1 satuan tingkatan flextime akan meningkatkan Jumlah Pesanan sebesar 0,662.

Tabel 5 .

Model Summaryb

\begin{tabular}{ccccc}
\hline Model & $\mathrm{R}$ & $\mathrm{R}$ Square & Adjusted R Square & Std. Error of the Estimate \\
\hline 1 & 0.633 & 0.401 & 0.397 & 2.956 \\
\hline
\end{tabular}

a. Predictors : (constant), Flextime

b. Dependent Variable : Jumlah Pesanan.

Sumber: Data ouput , 2018.

Angka $R$ square sebesar 0,401 menunjukkan bahwa Flextime mempengaruhi jumlah pesanan sebesar $40,1 \%$ sedangkan sisanya $59.9 \%$ dipengaruhi oleh faktor-faktor lain yang tidak diteliti dalam penelitian ini, untuk penelitian selanjutnya maka perlu dilakukan penelitian dengan menggunakan variabel diluar flextime seperti waktu kerja, kendaraan, hp baru dan sebagainnya.

Tabel 6.

Hasil Uji Indikator

\begin{tabular}{|c|c|c|c|c|c|}
\hline $\begin{array}{l}\text { Konsep } \\
\text { indikator }\end{array}$ & $\begin{array}{c}\text { Butir } \\
\text { pernyataan }\end{array}$ & $\frac{\mathrm{X}}{\text { Flextime }}$ & $\begin{array}{l}\text { Konsep } \\
\text { indikator }\end{array}$ & $\begin{array}{c}\text { Butir } \\
\text { pernyataan }\end{array}$ & $\begin{array}{c}\mathrm{Y} \\
\text { Jumlah Pesanan }\end{array}$ \\
\hline & 1 & 3,6 & \multirow{3}{*}{1} & 1 & 3,7 \\
\hline 1. & 2 & 3,8 & & 2 & 3,6 \\
\hline$?$ & 3 & 2,9 & & 3 & 3,8 \\
\hline 2. & 4 & 3,3 & \multirow{3}{*}{2} & 4 & 2,9 \\
\hline 3 & 5 & 3,5 & & 5 & 3,3 \\
\hline 3. & 6 & 4,0 & & 6 & 3,6 \\
\hline
\end{tabular}

Sumber: Data diolah 2018.

Berdasarkan tabel tersebut konsep tertinggi pada variabel flextime $(\mathrm{X})$ adalah pada indikator konsep 3 butir pernyataan ke 6 seperti semakin banyak waktu luang memberikan banyak kesempatan mendapat pesanan., dan yang paling rendah pada indikator konsep ke 2 butir pernyataan ke 3 gojek pekerjaan sampingan yang mengunttungkan. Selanjutnya pada Jumlah Pesanan ( $Y$ ) indikator konsep tertinggi pesanan pada konsep 1 butir pernyataan ke 3 promo yang diberikan menjadi motifasi bekerja dan yang terendah pada konssep 2 butir pernyataan ke empat poin menentukan Jumlah Pesanan. Kemudian penulis menyimpulkan hasil penelitian dalam gambar berikut :
Berdasarkan gambar tersebut dapat diartikan bahwa jumlah pesanan dipengaruhi oleh flextime terutama pada semakin banyak waktu luang memberikan banyak kesempatan mendapatkan pesanan dan pengaruh terkecil terletak pada indikator pengisi waktu dengan pernyataan Gojek sebagai pekerjaan sampingan yang menguntungkan bagi anda serta pada indikator jumlah pesanan pernyataan yang terbesar adalah pada promo yang diberikn Gojek memberikan motivasi bekerja serta pernyataan terendah terletak pada pernyataan poin menentukan Jumlah pesanan. Hasil penelitian ini membuktikan hipotesis alternatif diterima dan hipotesis objektif ditolak. 
Gambar 2

Full model penelitian

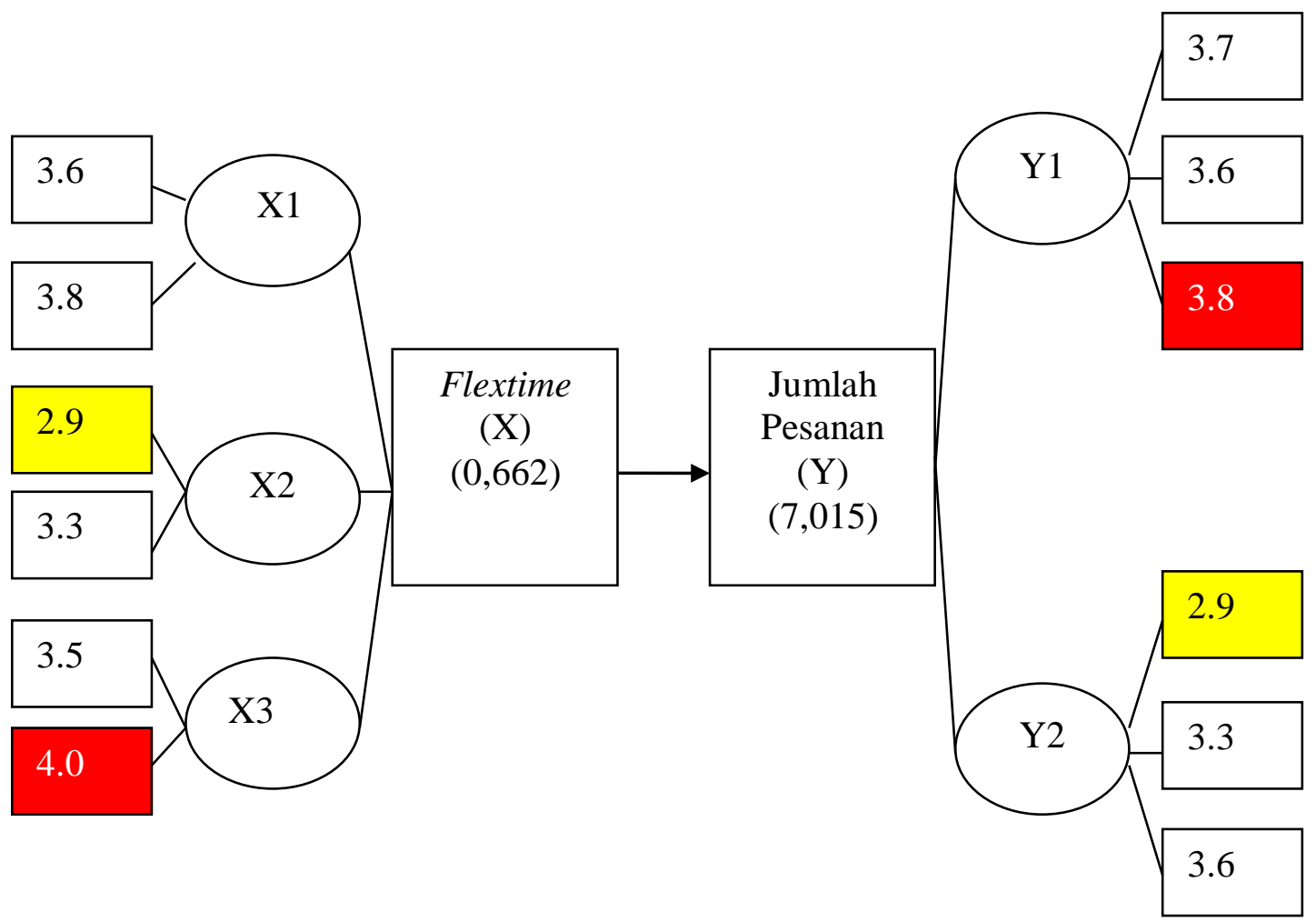

Sumber: Data diolah, 2018.

\section{SIMPULAN DAN SARAN}

\subsection{SIMPULAN}

Pengaruh variabel flextime $(X)$ terhadap Jumlah pesanan ( $Y$ ) sebesar $40,1 \%$. Berdasarkan uji flextime terhadap jumlah pesanan driver Gojek Bandar Lampung signifikan pada uji t. Penulis dapat menarik kesimpulan bahwa benar terdapat pengaruh flextime terhadap Jumlah Pesanan Gojek Bandar Lampung.

\subsection{Saran}

Flextime menjadi salah satu faktor yang mempengaruhi Jumlah Pesanan, oleh karena itu driver Gojek Bandar Lampung menerapkan waktu luang agar dapat membuat aspek waktu luang lebih baik sehingga dapat mencapai efektifitas. Mengenai flextime (waktu luang) agar driver memanfaatkan waktu luang bekerja tidak hanya bekerja di Gojek namun mempunyai pendapatan yang lain secara efektif agar menguntungkan driver Gojek Bandar Lampung.

\section{DAFTAR PUSTAKA}

Adisasmita, Rahardjo. 2015. Analisis Kebutuhan Transportasi. Yogyakarta: Graha IImu

Adisasmitha, Sakti Adji. 2011. Perencanaan Pembangunan Transportasi. Yogyakarta: Graha IImu

-------- 2014. Transportasi Komprehensif dan Multimoda. Yogyakarta: Graha IImu

Arikunto. (2010). Prosedur Penelitian: Suatu Pendekatan Praktek. Jakarta: Rineka Cipta.

Azhar Arsyad. (2009). Media Pembelajaran. Jakarta : PT. Raja Grafindo Persada

Azwar, S. (2013). Reliabilitas dan Validitas. Yogyakarta: Pustaka Pelajar.

Basu Swastha, 2008, Manajemen Pemasaran Analisis Perilaku Konsumen, Liberty, Yogyakarta.

Nurhasan, Dan Cholil. (2007). Modul Tes dan Pengukuran Keolahragaan. 
Bandung: Universitas Pendidikan Indonesia.

Nurhasan, dkk.(2008).

Modul Statistika.Bandung: FPOK Universitas Pendidikan Indonesia.

Santoso, Singgih. (2006). Menguasai STATISTIK di Era Informasidengan SPSS 15. Jakarta: Media Komputindo Kelompok Gramedia.

Sugiyono. 2012. Metode Penelitian Kuantitatif Kualitatif dan R\&D. Bandung: Alfabeta. Alfabeta. Sugiyono. 2013.

Umar, Husein. Statistika untuk Penelitian. Bandung : Alfabeta. 2008. Metode Ramalan Kuantitatif untuk Perencanaan Ekonomi \& Bisnis. Jakarta : Rineka Cipta.

Sugiyono. 2012.Metode Penelitian Bisnis. Bandung : Alfabeta. Sugiyono. 2013. Metode Penelitian Manajemen.
Bandung : Alfabeta Sugiyono. 2013. Metode Penelitian Kuantitatif Kualitatif dan $R \& D$. Bandung :

Zulfikli Amsyah, MLS. 2005. Manajemen Sistem Informasi. PT Gramedia Pustaka Utama. Jakarta.

http://rumushitung.com/2013/01/23/tabel-t-dancara-menggunakannya/ http://rumushitung.com/2013/06/08/tab el-r-statistika-dan-cara-membacanyal. http://ylki.or.id diakses 15 april 2018.

Sumber : PT Gojek Indonesia.com diakses tanggal 10 april 2018 jam 10.00 wib 2018.

Sumber https://www.tempo.co/tag/go-jekindonesia.diakses jam 10.00 WIB 2018.

Sumber : PT Gojek Indonesia.com diakses tanggal 10 april 2018 jam 10.00 wib.

https://Gojek-Jenis-Jenis-Layanan-GoJek tanggal 11 april 2018. 